\title{
Eating Disorder of a Muslim American "Hijabi" Woman: Case Study and Cultural Formulation
}

\author{
Shireen Musleh \\ Licensed Clinical Professional Counselor \\ Khalil Center, Glen Ellyn, Illinois, USA
}

\begin{abstract}
This single-participant case study highlights the clinical experiences of a Muslim American hijabi (adherence to Islamic dress code) woman, with emphasis on the cross-cultural and religious components that influence her mental illness. This case conceptualization illustrates body-image issues that Muslim women can face in western cultures, despite their religious values regarding the covering of the body and modest dress. Biopsychosocial factors are indicated to influence an eating disorder including, and are not limited to, family influences, genetics, cultural pressures, and life events.
\end{abstract}

\section{Identifying Information}

Sarah is a 25-year-old, single, heterosexual, Muslim American woman. She was born into a household of a first-generation Arab Muslim father and a white Muslim convert mother. Due to her religiously motivated choice of Islamic clothing and head-covering, she considers herself a "hijabi". She speaks English at home, but has learned to speak Arabic fluently at the age of 19 . She was born and raised in Florida, where she completed her high school education, as well as her undergraduate studies. Her mother is a health professional and her father was a physician before he passed away from an illness. She moved to Illinois for graduate school immediately after receiving her undergraduate degree, where she is completing a master's program. She currently lives alone on the school campus. She is the eldest of her siblings, which include two sisters 
and one brother, all residing in Florida with their mother. She has no physical disabilities and states that she excels academically. She is currently employed on the university campus part-time, but actively searching for full-time employment off campus, since she is in her last semester of the master's program.

\section{Chief Complaint}

Sarah presented to the initial psychotherapy session, at Khalil Center, a religiously oriented social and spiritual community wellness center, with an intense expression of sadness. She was tearful and had a low affect. She expressed a strong desire to take control of an eating disorder that she has struggled with for years. She stated that she wanted to build self-compassion and self-esteem, as well as understand what caused her to have such a strong obsession with food and an insecure body image. Sarah also complained about financial struggles, and identified it as a cause of a great deal of anxiety and stress. She wanted to learn about her emotions and how to better regulate them. She also stated that she wanted to learn to love herself. She consistently complained of an overwhelming feeling of guilt that she experienced almost daily.

\section{History of Present Illness}

Sarah stated that she has struggled with her body image for at least the past ten years. She recalled instances from her childhood, when she felt insecure about her physical appearance. She was diagnosed with Binge-Eating Disorder in 2015. She reported that she struggled with binge-eating episodes since the age of fifteen, after her father passed away from an illness. Her binging occurred daily when she moved away from her family for undergraduate study. For the past two years, her binge episodes drastically decreased to a few times per month.

Depressive symptoms, including tearfulness, hopelessness, low affect, and worthlessness were initially experienced by Sarah after the loss of her father. She stated that her depression fluctuated in intensity but was persistently present. She reported past suicidal ideation, but that she never planned or attempted suicide. She reported a decrease in suicidal ideation due to increase in religiosity. She also reported frequently experiencing feelings of intense anger and irritability toward herself, followed by strong feelings of guilt and shame. 


\section{Past Psychiatric History}

After initial reluctance, Sarah sought out psychotherapy services on a few occasions in the past two years by two non-Muslim, white, female clinicians. She reported past restrictive eating behavior and preoccupation with dieting, binge eating, and body image concerns. She stated that cognitive behavioral techniques helped her gain some control over her eating disorder, but she would fall right back into the patterns of the disorder once she discontinued therapy. The focus of past treatment was on reducing binge episodes and regulating her eating schedule. She has never been hospitalized for any mental health related issues. There is no history of prescription of psychotropic medication.

\section{General Medical History}

Sarah reported having no significant medical illnesses. She reported that she periodically visits her primary care physician and is prescribed acne medication called Azelex cream. This medication is not associated with any of the presented psychological symptoms.

\section{History of Substance Abuse}

Sarah reported having no history of substance use or abuse. She has never engaged in the recreational use of alcohol or any other form of drug use. She credits her abstinence to her strong faith in Islam. She stated that her faith kept her away from sins of that nature.

\section{Psychosocial and Developmental History}

Sarah reported having a "normal" childhood. She stated that she has never experienced any trauma. She denied any physical, emotional or sexual abuse. Sarah reported being body conscious since early childhood. She stated that she was always jealous of her two siblings who were thin despite their excessive eating habits. "They have my mother's genes; my sister and I have my father's genes."

Her father was overweight, which contributed to his illness at the end of his life. In Sarah's mind, her father's excessive weight caused his early death, which left her abandoned without a father at the young age of 15 . She believes that this life event may have something to do with her obsession with her weight and food intake. She also expressed resentment toward the fact that she has 
no father to help fund her schooling like many of her Arab friends. She made these comments when discussing her anxiety associated with her economic hardships. It seemed that she partially blames her father for not being there to help her, and being overweight had something to do with this sense of "abandonment."

Sarah reported being very emotionally expressive in her family. All family members are usually aware of her eating disorder and emotional states, including her mother, siblings, grandmother, uncles, and aunts, etc. She stated that her biggest emotional and financial support throughout her life has been her mother.

Sarah indicated that she has many friends, although, most do not know about her internal struggles. She reported spending a significant amount of time with friends from school, but still experiences loneliness. When asked to describe her friends, she focused on the individuals who she suspects are struggling with their weight and eating. Descriptions of her friends were primarily of their physical appearance. The majority of her friends are of Arab descent. When brought to her attention, she was pleasantly surprised, and stated, "I never noticed, but I just love Arabs; maybe I am holding on to my dad somehow."

Sarah expressed her desire to marry an Arab Muslim man. When asked why that is important to her, she was unable to answer. The only concern she reported having with Arab men in general was regarding her belief that Arab men are overly critical of their wives' physical appearance. This overgeneralization contributes to her fears of being rejected by Arab men. She also reported familial pressures on her to get married. It should be noted that she is also placing pressure on herself to find a compatible spouse. She used social apps to find a Muslim spouse but was unsuccessful. She reported being rejected based on her physical appearance.

\section{Family History}

As mentioned above, Sarah is the eldest of four siblings in her family. Her father passed away when she was a teenager. Her mother, a health professional, resides in Florida with Sarah's three siblings. They live near her maternal uncles, aunts, grandparents, and other extended family members. Sarah has no relatives residing in Illinois, where she currently lives. Her mother is a big source of emotional and financial support. Although she struggles with the dynamic of the relationship, Sarah stated that she is closest to her mother than anyone else she knows. No familial psychiatric history was reported. It was reported that her father suffered emotionally during the last few years of his life, although never officially given a psychiatric diagnosis. She reported that one of 
her youngest sisters struggles with her body image and may be experiencing emotional distress.

\section{Initial Mental Status Examination}

Sarah was well-groomed with average height and slightly above-average weight. She dressed appropriately in casual clothing that falls in line with the traditional Islamic dress code, including hijab. She attended all therapy sessions alone and was punctual. Sarah demonstrated poor eye contact and appeared to be anxious during most therapy sessions. She was often tearful during sessions, while speaking in a rapid and excessive manner. She displayed depressed mood and was often crying. She was cooperative and trusting of the clinician. While she appeared to be disorganized, she was able to concentrate well. Judgement and insight into her problems were both moderate. Her thought processes were disorganized and obsessive about weight and food intake. She displayed flight of ideas at times and mild paranoia regarding other people's perception and thoughts of her. She had impaired impulse control with food. She denied suicidal or homicidal ideation, plan or intent, but reported past suicidal ideation. Her denial was convincing. Rapport was easily established.

\section{DIAGNOSTIC FORMULATION}

Sarah meets the criteria for the following DSM-5 diagnoses:

296.32, F33.1 Major Depressive Disorder, Recurrent Episode, Moderate (Principal Diagnosis)

307.51, F50.8 Binge-Eating Disorder

\section{Case Summary}

After initial assessment, Sarah met the criteria for the DSM-5 diagnosis of Major Depressive Disorder and Binge-Eating Disorder. The symptoms included recurrent episodes of consuming a large amount of food in a short period of time, compared to what others might eat, with episodes characterized by experiencing a lack of control and significant distress regarding binge eating, eating until feeling uncomfortably full while alone due to embarrassment, followed by feelings of disgust of oneself and a strong sense of guilt after overeating. There is an absence of compensatory behavior, such as purging. Major Depressive symptoms included persistent sadness and low affect, crying spells, feelings of guilt and worthlessness, past thoughts of suicide, irritability and feelings of hopelessness. She exhibited paranoid cognitive patterns regarding how others 
judge and perceive her. She did not report any medical conditions. She discussed difficulty in finding employment, and identified her economic status as a stressor, as well as the cultural pressures to find a marriage partner. She exhibited mild symptoms that interfere with her social functioning, but she generally functioned pretty well and had some meaningful interpersonal relationships.

\section{COURSE OF TREATMENT}

As part of the assessment process with Muslim clients, Sarah was asked to fill out two questionnaires, the Muslim Experiential Religiousness (MER) Scale (Ghorbani et al., 2014) and the Islamic Positive Religious Coping Scale. She displayed a positive experience toward religion and Allah as well as a moderate level of positive religious coping skills. Sarah was very pleased to have religious assessment and focus emphasized in her treatment. The goal was to increase the positive Islamic religious coping behaviors during the course of her treatment.

Sarah also completed the Brief Symptoms Inventory at the initial therapy session. She displayed high scores on items including "feelings being easily hurt, feeling that people are unfriendly or dislike you, feeling inferior to others, feeling that you are watched or talked about by others, feeling very selfconscious with others, feelings of guilt, and the idea that something is wrong with your mind." The obtained BSI assessment score was used to obtain a GSI score (Global Severity Index). Any score of 63 or above places the client in the clinical range. Sarah's GSI score was 71. A follow-up BSI assessment will be conducted periodically to monitor change in symptoms. Despite the reported positive experience toward religion and Allah as well as a moderate level of positive religious coping skills, Sarah has a high BSI score. This could be due to superficial coping or inaccurate self-report. According to Ghorbani and colleagues (2014), depressive and anxiety symptoms decrease with increased religious coping skills. It is possible that Sarah's bias is that she wants to present a better religious image to others, including the clinician, out of fear of judgement.

Since Sarah presented with depressive symptoms, Beck's Depression Inventory was used to assess the level of depression. Her total score was 22, which fell in the moderately depressed range. A follow-up evaluation would take place before termination of treatment to ensure that depressive symptoms are in remission.

The course of treatment utilized individual psychotherapy that began primarily focusing on helping Sarah improve her self-esteem and self-acceptance by building self-compassion. Compassion-focused therapy was used, because Sarah had high levels of shame and self-criticism, and had great difficulty in 
being kind to herself or having self-compassion. These feelings are rooted in her history of neglect by losing her father as well as lack of affection she experienced from her mother. Acceptance and commitment therapy was used during initial sessions to help Sarah realize and clarify her values and what is important to her, and further help her align her behaviors accordingly. Diaphragmatic breathing techniques were presented in therapy to teach Sarah to reduce the high levels of stress and anxiety when having intrusive negative thoughts.

Religious therapeutic modalities were utilized with Sarah (Keshavarzi \& Haque, 2013). The concept of tawwakul to increase and strengthen her reliance on God regarding the aspects of her life that are out of her control (Haque \& Keshavarzi, 2013). This included how others may perceive her or her inability to obtain employment as quickly as she would like. The goal was to train Sarah to focus on the elements of her life that are within her control and learning to become present in the moment. Islamic religious psychotherapy was used to help Sarah identify unproductive beliefs and modify or replace them with beliefs consistent with her religious beliefs from Islam, using Hamdan's (2008) Islamic cognitive restructuring techniques. The clinician helped modify Sarah's perception to accept and be satisfied with what she has and to put complete trust (tawwakul) in God and His divine decree, leading to Islamic contentment (Haque \& Keshavarzi, 2013).

The Qur'an and hadith were used to introduce an Islamic concept of a behavioral log, muhaseba, that was used to help change Sarah's impulsive bingeeating behavior. Muhaseba, or taking self-account on a daily basis, allowed her to objectively measure and monitor her behavior change over the course of treatment (Haque \& Keshavarzi, 2013).

Other therapy goals included increasing spiritual and religious practices in order to help Sarah better cope with symptoms and stressful events. Given Sarah's remarks regarding her feelings of decreased level of faith, accompanied by feelings of guilt and worthlessness, it was asked of her to "send an abundance of salutations upon the Prophet Muhammad" daily. This meditiative practice allowed her to feel closer to the Prophet and to feel motivated to emulate him. In addressing Sarah's paranoid thoughts, she was asked to recite Qur'an regularly as well as seek refuge from evil and make supplications to rid her of illnesses. This is referred to as Ruqyah in Islam (Haque \& Keshavarzi, 2013).

\section{CULTURAL FORMULATION}

\section{Cultural Identity}

Sarah was born and raised in the United States. Her father was born and raised in Egypt, and immigrated to the US as an adult to obtain work. He married 
Sarah's mother, a white Muslim convert. Sarah stated that she identifies more with her Arab culture than with her white American culture. She stated how content and happy she felt when she visited Egypt for the first time in 2016.

Sarah is an active participant in the Muslim faith, by praying five times a day, fasting the month of Ramadan each year, and observing a degree of dress code referred to as hijab. She has made remarks expressing how others outside of her faith tend to judge her and do not understand her. These paranoid thoughts seem to isolate her from others who are not Muslim. She has a strong attachment to her Muslim identity.

\section{Language}

Sarah dedicated a great deal of time learning the Arabic language, motivated by her love for her Arab and Muslim cultures. She displayed a sense of comfort and happiness when Arabic was used during therapy sessions, and was proud of her ability to speak it fluently. This was used to help improve her self-esteem, because it exemplified an important aspect of her self-worth as a Muslim. She can read and understand the Qur'an in its original Arabic text and uses it to connect to Allah. Resentment was displayed by Sarah toward her family who do not speak Arabic fluently. She recalled memories of her father speaking Arabic to her when she was younger. The Arabic language is another form of connection to her father.

\section{Cultural Explanations of the Individual's Illness}

Sarah fully acknowledges her mental illnesses and is overly preoccupied with how to resolve them. She has made numerous efforts to better understand her mental illnesses and is searching for an explanation.

Sarah's identity issues included conflict between identifying as white or Arab, which further exacerbated her symptoms. She stated that she "blames her white side for the eating disorder." This seems to fall in line with a broader phenomenon observed in the Muslim community. A previous study described a pattern of Muslims generally forming their identity according to religious and family values (Ahmad \& Amer, 2012).

Sarah's recent trip to Egypt further exacerbated her identity issues. She felt welcome and loved as a visitor in Egypt by paternal relatives, but was left feeling unloved and unwelcome when she returned to America. She stated that she felt that way given the current political anti-Muslim rhetoric in America. She also stated that, although she loves her family a great deal, she does not relate to them as well as she used to, because they are not as religious or interested in religion as much as she is. She feels disconnected from her white family mem- 
bers and holds on to the Arab part of her identity to feel closer to her father. Another explanation for her strong attachment to Egypt was the hospitality she experienced there made her feel loved and wanted. This resolved her sense of isolation. She stated, "Because I struggle to accept myself, and everyone in Egypt was in love with me and showered me with love, affection, and hospitality, and I spoke Arabic, I felt like I was part of society."

She has also mentioned that she believes the loss of her father at an early age to a health condition that involved his obesity may have contributed to her fears of becoming overweight like her father and consequently becoming ill and dying an early death. She stated that part of her grief is holding on to her dad in some way with this eating disorder. It is a constant reminder that she is struggling like her father did.

\section{Cultural Factors Related to Psychosocial Environment And Levels of Functioning}

Sarah is an overachiever academically and demonstrates a strong-willed, independent persona around her friends and acquaintances. She stated that most people around her are surprised to learn about her low self-esteem and hatred of herself. She stated that she does this due to the social pressures of her family to be a successful and independent Muslim woman. Her mental health struggles are affecting her relationships and level of functioning.

The superficial religious interpretation of psychological symptoms seem to enforce the minimization of symptoms of mental illness in the Arab community. Cultural and religious beliefs are intertwined at times and become indistinguishable from each other. This leads to beliefs that a Muslim should repress emotions and not express them; all good and bad comes from God, adverse life experiences are explained as a test from God, and that Muslims are judged by performance during this examination. Although patience is an important principle in the Islamic tradition, cultural stigma often discourages the healthy and appropriate expression of psychological distress or acknowledgement of actual mental illness that requires professional help. Culturally, such help may be seen as negating trust in God, while religiously according to some positions within the Sunni tradition, religiously incumbent upon adherents to seek treatment. This cultural stigma added to Sarah's initial reluctance to seek treatment. When she learned about Khalil Center, she was encouraged to reach out for help. She claimed during the initial sessions that she regrets not searching for and reaching out to Khalil Center much sooner. The cultural and social pressures definitely added to her low self-worth and self-esteem. Sarah stated that she feels guilty for feeling the way she does. She explained her symptoms as a result of being ungrateful to God. 
Sarah reported confusion regarding her own expectations of wearing hijab to eliminate her eating disorder. She wanted to quickly rid herself of the selfdestructive patterns of her binge-eating episodes, so part of her decision to wear the hijab was to no longer need to "fit into society's beauty expectations." But she quickly realized that the hijab did not help her skewed body-image issues. She did not stop caring about her appearance like she expected. Hijab did not rid her of her mental illness. This letdown increased her depressive symptoms.

\section{Cultural Elements of the Clinician-Patient Relationship}

Sarah reported at intake that she has considered and visited non-Muslim therapists before finding a Muslim clinician. She stated that it is not as important for her therapist to share her cultural background, but that it was extremely important that the therapist share her religious values. She also marked that it was extremely important for religion/spirituality to be an essential part of the therapy process. Despite cultural sanctions on seeking help, a religiously oriented treatment center helped break that barrier down. Barriers for service delivery among Muslims is primarily that they seek religiously oriented psychotherapy. In this case, Sarah did not find success with a previous non-Muslim therapist, and terminated prematurely due to lack of religiously oriented treatment. The clinician at Khalil Center shared the normative practices and values of Sarah's culture. This helped build a strong therapeutic alliance quickly. Sarah seemed to trust the clinician easily.

It was at times difficult to communicate with Sarah during sessions. Her speech was rapid and she exhibited racing thoughts that influenced her to jump from subject to subject with little time to process the clinician's reflections or comments. She was anxious about time running out for each session. She was extremely eager to improve and resolve her mental illnesses quickly. The clinician was consistently reminding her to remain patient and that the process of psychotherapy takes time to create a significant change. Religious and cultural factors played a strong role in the development of Sarah's mental illnesses and their potential solutions. Sarah constantly brought up the idea that she "should not be feeling depressed because she does not have it bad in life." She feels a great deal of guilt for feeling the way she feels. She seemed to want a directive psychotherapy approach, where she can receive advice and find a quick fix, in order to relieve herself from the guilt. The stigma associated with coming to therapy for Muslim clients has to do with viewing it as an admission of weakness. Seeking help may mean that one has weakness in faith, in physical ability, and manifestation of a lack of a strong support system (Kobeisy, 2006). 


\section{DISCUSSION}

To successfully treat a Muslim American woman like Sarah, it is crucial to be aware and sensitive to the religious and cultural aspects of the case. In this particular case, religiously oriented psychotherapy overcame many barriers. Those working with religiously adherent Muslims should consider a spiritually integrated approach (Richards \& Bergin, 2005). Islam plays an important role in the lives of many Muslims, as it provides them with a comprehensive framework that influences their worldview (Haque \& Keshavarzi, 2013). Since many therapists encounter Muslim clients, special consideration must be made regarding the importance of the role of Islam in their lives and how this connects Muslims to their community (Keshavarzi \& Haque, 2013).

Regardless of the substantial mental health related issues Muslims face, many refuse to seek psychotherapy services (Haque et al., 2016). Hesitation to seek treatment is largely due to the lack of religiously oriented approaches to therapy. Other barriers to service delivery to Muslim clients include: (1) mistrust of service providers, (2) fear of treatment, (3) fear of racism and discrimination, (4) language barriers, (5) differences in communication and (6) issues of culture/religion (Inayat, 2007).

As seen in this case, there commonly is a reluctance to discuss issues openly due to perceived religious constraints. For example, the belief that mental health care is not compatible with the Islamic concept of tawwakul, of reliance on God and His divine decree. The therapist's Islamic-integrated approach may reframe the understanding of the Islamic concepts, in order to help the client understand that seeking mental health treatment does not go against Islamic values. A therapist who shares religious values of a Muslim client may be able to gain the trust of the client much quicker.

When a client identifies a disparity between actual behaviors and desired behaviors, a common technique in behavioral therapies is to use a form of behavior tracking or activity log, as a method to monitor behaviors and thoughts. Using the Qur'an and hadith to introduce the Islamic concept of taking selfaccount (muhaseba) may increase the client's commitment or motivation. Invoking Islamic terminology and concepts may be a more culturally congruent method of applying similar techniques from other therapeutic modalities (Haque \& Keshavarzi, 2013). In a spiritual context, muhaseba is different than other behavioral interventions in that it takes on an additional purpose of bringing oneself closer to God by means of correcting behaviors and thoughts. A practicing Muslim client would be more incentivized to incorporate this into their lives because of the added dimension of the potential attainment of closeness to God.

Regardless of which therapeutic approach is used with Muslim clients, mental health clinicians should modify their interventions to better fit the 
needs of their clients. Directly asking the clients about their values and preferences, instead of making assumptions, may help strengthen the therapeutic bond and develop a more effective religiously, spiritually, and culturally sensitive treatment plan.

\section{REFERENCES}

Amer, M. \& Ahmad, S. (2012). Counseling Muslims: Handbook of mental health issues and interventions. New York: Routledge. ISBN 978-0-415-98860-5

Beck, A. T., Ward, C. H., Mendelson, M., Mock, J., \& Erbaugh, J. (1961) An inventory for measuring depression. Archives of General Psychiatry, 4, 561-571. https://doi. org/10.1001/archpsyc.1961.01710120031004

Ghorbani, N., Watson, P. J., Geranmayepour, S., \&, Chen, Z. (2014). Measuring Muslim spirituality: Relationships of Muslim experiential religiousness with religious and psychological adjustment in Iran. Journal of Muslim Mental Health, 8, 7794. http://dx.doi.org/10.3998/jmmh.10381607.0008.105

Hamdan, A. (2008). Cognitive restructuring: An Islamic perspective. Journal of Muslim Mental Health, 3, 99-116. http://dx.doi.org/10.1080/15564900802035268

Haque, A., \& Keshavarzi, H. (2013). Integrating indigenous healing methods in therapy: Muslim beliefs and practices. International Journal of Culture and Mental Health,7, 297-314. http://dx.doi.org/10.1080/17542863.2013.794249

Haque, A., Keshavarzi, H., Khan, F., \& Rothman, A. (2016). Integrating Islamic traditions in modern psychology: Research trends in the last ten years. Journal of Muslim Mental Health, 10, 75-100. http://dx.doi.org/10.3998/jmmh.10381607.0010.107

Inayat, Q. (2007). Islamophobia and the therapeutic dialogue: Some reflections. Counselling Psychology Quarterly, 20, 287-293. doi:10.1080/09515070701567804

Keshavarzi, H., \& Haque, A. (2013). Outlining a psychotherapy model for enhancing Muslim mental health within an Islamic context. International Journal for the Psychology of Religion, 23, 230-249. http://dx.doi.org/10.1080/10508619.2012.712000

Kobeisy, A. N. (2006). Faith-based practice: An introduction. Journal of Muslim Mental Health, 1, 57-63. https://dx.doi.org/10.1080/15564900600697749

Richards, P. S., \& Bergin, A. E. (2005). A spiritual strategy for counseling and psychotherapy, 2nd ed. Washington, DC: American Psychological Association. http://dx.doi. org/10.1037/11214-000 